\title{
Fiscalização de hortas produtoras de verduras do município de Ribeirão Preto, SP
}

\author{
Monitoring of lettuce crops of Ribeirão Preto, SP, Brazil \\ Osvaldo M. Takayanagui', Luiza H.P. Febrônio², Alzira M. Bergamini ${ }^{3}$, Madalena H.T. Okino³, \\ Ana A.M.C. Castro e Silva ${ }^{4}$, Roseli Santiago ${ }^{4}$, Divani M. Capuano ${ }^{3}$, \\ Maria A. Oliveira ${ }^{3}$ e Angela M.M. Takayanagui ${ }^{5}$
}

\begin{abstract}
Resumo O consumo de verduras cruas desempenha importante papel na transmissão de várias doenças infecciosas pela freqüente prática de irrigação de hortas com água contaminada. $O$ objetivo deste estudo é a avaliação das condiçồes higiênico-sanitárias de todas as hortas produtoras de verduras de Ribeirão Preto, SP com implantação de um sistema de fiscalização. $A$ análise laboratorial de 129 hortas revelou irregularidades em 20,1\% delas, destacando-se elevada concentração de coliformes fecais em 17\%, presença de Salmonella em 3,1\% e de vários enteroparasitas (Ascaris sp, Ancylostomidae, Strongyloides sp, Hymenolepis nana e Giardia sp) em $13,1 \%$. A repetição da análise das hortas irregulares determinou a interdição definitiva de uma delas; todas as demais foram aprovadas, comprovando a eficácia do sistema de fiscalização, particularmente com a implantação, inédita no país, do certificado de vistoria sanitária.
\end{abstract}

Palavras-chaves: Horta. Verdura. Coliformes fecais. Salmonella. Cisticercose.

Abstract The ingesting of raw vegetables plays an important role in the transmission of several infectious diseases due to the high frequency of irrigation with wastewater. The objective of this study was to evaluate the sanitary conditions of all lettuce producing crops in Ribeirão Preto through microbiological and parasitological analysis of both irrigation water and lettuce together with the implantation of an effective crop monitoring. Laboratory analysis of 129 crops showed irregularities in $26(20.1 \%)$ of these: high concentration of fecal coliforms in 17\% of the lettuce, presence of Salmonella in 3.1\% and several enteroparasites (Ascaris sp. Ancylostomidae, Strongyloides sp, Hymenolepis nana, and Giardia sp) in 13.1\%. Persistent irregularities determined the definitive closing down of one producer; all of the remaining 128 crops were eventually approved, thus demonstrating the efficacy of lettuce crop monitoring. Crops approved in the laboratory analysis were awarded a Sanitary Inspection Certificate - an unprecedented procedure in our Country - that resulted in a better acceptance of the monitoring.

Key-words: Lettuce. Vegetable. Fecal coliforms. Salmonella. Cysticercosis.

\footnotetext{
1. Departamento de Neurologia da Faculdade de Medicina de Ribeirão Preto da Universidade de São Paulo; 2. Divisão de Vigilância Sanitária da Secretaria da Saúde do Município de Ribeirão Preto; 3. Instituto Adolfo Lutz, Laboratório I de Ribeirão Preto, Secretaria da Saúde do Estado de São Paulo; 4. Divisão de Vigilância Epidemiológica da Secretaria da Saúde do Município de Ribeirão Preto; 5. Disciplina de Saúde Pública da Escola de Enfermagem de Ribeirão Preto da Universidade de São Paulo, Ribeirão Preto, SP, Brasil. Apoio financeiro: Trabalho realizado com auxílio financeiro do Conselho Nacional de Desenvolvimento Científico e Tecnológico (CNPq), processo no $300336 / 93-4$.

Endereço para correspondência: Dr. Osvaldo M. Takayanagui. Depto de Neurologia/FMRP/USP. Av. Bandeirantes 3900, 14048-900 Ribeirão Preto, SP, Brasil.

Tel: 5516 623-3996; fax: 5516 633-0866.

e-mail: otakay@rnp.fmrp.usp.br

Recebido para publicação em 6/4/99.
} 
O consumo de verduras cruas constitui importante meio de transmissão de várias doenças infecciosas pela freqüente prática de irrigação de hortas com água contaminada por matéria fecal ou mesmo adubadas com dejetos humanos 5718192021 .
O presente trabalho teve como objetivo a análise das condições higiênico-sanitárias de todas as hortas produtoras de verduras do município de Ribeirão Preto, SP, com implantação de um sistema de fiscalização.

\section{MATERIAL E MÉTODOS}

Elaboramos o cadastro de todas as hortas localizadas no município de Ribeirão Preto, através de busca ativa, visando a caracterização da área de cultivo, fonte da água de irrigação e tipo de hortaliça produzida. Do total de 150 hortas cadastradas, 21 estavam desativadas por ocasião da fiscalização, não sendo possível a coleta de material. A presente investigação foi baseada na avaliação higiênico-sanitária de todas as 129 hortas em atividade produtiva, no período de agosto de 1995 a julho de 1997. A área de cultivo variou de $200 \mathrm{~m}^{2}$ a $314.000 \mathrm{~m}^{2}$ (mediana de $10.000 \mathrm{~m}^{2}$ ), com a seguinte distribuição geográfica: 77 (51,3\%) localizadas na zona oeste, $36(24 \%)$ na norte, $23(15,3 \%)$ na sul e 14 $(9,3 \%)$ na leste.

A fiscalização foi realizada pelo serviço de Vigilância Sanitária da Secretaria da Saúde do Município, com inspeção da fonte da água utilizada na irrigação e coleta de 2 amostras aleatórias de verduras de folha e uma amostra da água de irrigação. Dentre as verduras foi dada preferência à alface e, na sua ausência, ao almeirão ou ao agrião.

A verdura foi acondicionada individualmente em sacos plásticos de primeiro uso, sem contato manual e a água recolhida em frasco esterilizado de $250 \mathrm{ml}$. Após identificação, o material foi encaminhado ao Instituto Adolfo Lutz de Ribeirão Preto para análises microbiológica e parasitológica, segundo Gelli et $\mathrm{al}^{10} \mathrm{e}$ Marzochi ${ }^{16}$, com algumas modificações.

A análise microbiológica da verdura foi fundamentada na determinação do número mais provável de bactérias do grupo coliforme de origem fecal (NMP/g) e na pesquisa de Salmonella $s p$, segundo metodologia preconizada pela American Public Health Association ${ }^{1}$ e de acordo com o estabelecido pela legislação em vigor ${ }^{9}$.
O cálculo do NMP de coliformes fecais foi efetuado com o auxílio da tabela de Hoskins ${ }^{13}$.

A análise microbiológica da água de irrigação, segundo técnica recomendada pela American Public Health Association ${ }^{2}$, teve como indicador do grau de contaminação fecal o NMP de coliformes fecais $/ 100 \mathrm{ml}$, segundo legislação em vigor $^{6}$.

A análise parasitológica foi realizada após duas lavagens. Na primeira, por enxaguadura, o saco plástico contendo a verdura foi agitado manualmente por 30 segundos após introdução de $250 \mathrm{ml}$ de água destilada. Na segunda, após desfolhamento, cada folha da verdura foi esfregada com um pincel chato $n^{0} 16$ num recipiente de vidro com $250 \mathrm{ml}$ de água destilada. A água das lavagens foi deixada em repouso em cálice cônico por 24 horas após filtragem em gaze de 8 dobras. O sedimento então obtido foi analisado ao microscópio por exame direto e após centrífugo-flutuação em sulfato de zinco. Outra parte do sedimento foi utilizada na pesquisa de oocistos de Cryptosporidium sp por adição de formalina tamponada a $10 \%$, concentração pela técnica do formol-éter e coloração do esfregaço por Kinyoun ${ }^{15}$.

O resultado final do exame laboratorial, fornecido pelo Instituto Adolfo Lutz, foi entregue aos produtores. As hortas aprovadas receberam - Certificado de Vistoria Sanitária, emitido pela Secretaria de Saúde do Município. Aquelas com resultados indicativos de contaminação da água ou das verduras receberam um auto de infração e foram intimadas a providenciar as devidas modificações para nova coleta de material num prazo aproximado de 15 dias. A persistência de resultados indicativos de contaminação nessa segunda análise determinou a aplicação de uma multa pecuniária e, na sua reincidência, a interdição definitiva da horta.

\section{RESULTADOS}

Do total de 129 hortas avaliadas, 26 (20,1\%) apresentaram irregularidades: 24 em verduras, uma na água de irrigação e outra em ambas
(Tabela 1). O exame microbiológico revelou presença de elevada concentração de coliformes fecais na verdura de 22 hortas e de Salmonella 
Tabela 1 - Características das 26 hortas apresentando irregularidades nos exames microbiológico e parasitológico.

\begin{tabular}{|c|c|c|c|c|c|c|c|}
\hline \multirow[b]{2}{*}{ Horta } & \multirow[b]{2}{*}{ Zona } & \multirow[b]{2}{*}{$\begin{array}{c}\text { Área de } \\
\text { plantio }\left(\mathrm{m}^{2}\right)\end{array}$} & \multirow[b]{2}{*}{$\begin{array}{l}\text { Tipo de } \\
\text { verdura }\end{array}$} & \multicolumn{2}{|c|}{ Água de irrigação } & \multicolumn{2}{|l|}{ Verdura } \\
\hline & & & & $\begin{array}{c}\text { fonte de } \\
\text { água }\end{array}$ & $\begin{array}{c}\text { exame } \\
\text { microbiológico }\end{array}$ & $\begin{array}{c}\text { exame } \\
\text { microbiológico }\end{array}$ & $\begin{array}{c}\text { exame } \\
\text { parasitológico }\end{array}$ \\
\hline 1 & sul & 10000 & alface & poço de superfície & adequado & $\begin{array}{l}\text { Salmonella Abaetetuba } \\
\text { coliformes fecais }>2280 / g\end{array}$ & negativo \\
\hline 2 & sul & 3000 & alface & poço de superfície & adequado & Salmonella Schwarzengrund & Ancilostomídeos \\
\hline 3 & leste & 24000 & alface & $\begin{array}{l}\text { mina próxima } \\
\text { a córrego }\end{array}$ & adequado & coliformes fecais $1100 / \mathrm{g}$ & negativo \\
\hline 4 & leste & 6000 & alface & mina & adequado & coliformes fecais $550 / g$ & negativo \\
\hline 5 & oeste & 200 & almeirão & rede pública & adequado & coliformes fecais $3960 / \mathrm{g}$ & negativo \\
\hline 6 & oeste & 6000 & alface & poço de superfície & adequado & coliformes fecais $874 / g$ & $\begin{array}{l}\text { Ancilostomídeos } \\
\text { Entamoeba sp }\end{array}$ \\
\hline 7 & oeste & 15000 & alface & mina & adequado & coliformes fecais $456 / g$ & $\begin{array}{l}\text { Ancilostomídeos } \\
\text { Entamoeba sp }\end{array}$ \\
\hline 8 & oeste & 1000 & alface & mina & adequado & coliformes fecais $480 / g$ & $\begin{array}{l}\text { Ancilostomídeos } \\
\text { Entamoeba sp }\end{array}$ \\
\hline 9 & sul & 200 & alface & poço de superfície & adequado & coliformes fecais $609 / \mathrm{g}$ & $\begin{array}{l}\text { Ancilostomídeos } \\
\text { Entamoeba sp }\end{array}$ \\
\hline 10 & norte & 14000 & almeirão & poço de superfície & adequado & Salmonella Enteritidis & $\begin{array}{l}\text { Strongyloides sp } \\
\text { Ancilostomídeos } \\
\text { Entamoeba sp }\end{array}$ \\
\hline 11 & norte & 800 & almeirão & rede pública & adequado & coliformes fecais $460 / g$ & Entamoeba sp \\
\hline 12 & leste & 1000 & alface & mina & $\begin{array}{c}\text { coliformes fecais } \\
5400 / 100 \mathrm{ml}\end{array}$ & $\begin{array}{l}\text { Salmonella hountenae } \\
\text { coliformes fecais } 3840 / g\end{array}$ & $\begin{array}{c}\text { Giardia } s p \\
\text { Entamoeba } s p\end{array}$ \\
\hline 13 & sul & 1000 & alface & água de córrego & $\begin{array}{c}\text { coliformes fecais } \\
1700 / 100 \mathrm{ml}\end{array}$ & não realizado & não realizado \\
\hline 14 & oeste & 5000 & alface & poço semi-artesiano & adequado & coliformes fecais $>2640 / g$ & Hymenolepis nana \\
\hline 15 & norte & 1000 & rúcula & rede pública & adequado & coliformes fecais $1760 / \mathrm{g}$ & negativo \\
\hline 16 & norte & 40000 & alface & poço semi-artesiano & adequado & coliformes fecais $>3576 / g$ & Entamoeba sp \\
\hline 17 & norte & 10000 & alface & poço de superfície & adequado & coliformes fecais $225 / \mathrm{g}$ & negativo \\
\hline 18 & norte & 1400 & alface & poço de superfície & adequado & coliformes fecais $2640 / \mathrm{g}$ & $\begin{array}{l}\text { Ancilostomídeos } \\
\text { Entamoeba sp }\end{array}$ \\
\hline 19 & oeste & 10000 & almeirão & mina & adequado & coliformes fecais $598 / g$ & negativo \\
\hline 20 & oeste & 5000 & almeirão & poço de superfície & adequado & coliformes fecais $406 / \mathrm{g}$ & Entamoeba sp \\
\hline 21 & sul & 1800 & agrião & poço de superfície & adequado & coliformes fecais $222 / g$ & Ancilostomídeos \\
\hline 22 & leste & 2800 & agrião & poço de superfície & adequado & coliformes fecais $786 / \mathrm{g}$ & Ancilostomídeos \\
\hline 23 & sul & 10000 & almeirão & água de córrego & adequado & coliformes fecais $783 / g$ & negativo \\
\hline 24 & oeste & 18000 & alface & poço semi-artesiano & adequado & coliformes fecais $>2640 / g$ & $\begin{array}{l}\text { Hymenolepis nana } \\
\text { Ancilostomídeos }\end{array}$ \\
\hline 25 & oeste & 14000 & alface & poço semi-artesiano & adequado & coliformes fecais $1200 / \mathrm{g}$ & Ancilostomídeos \\
\hline 26 & oeste & 5000 & alface & poço de superfície & adequado & negativo & Ascaris sp \\
\hline
\end{tabular}

em 4. O exame parasitológico de verduras evidenciou contaminação por vários enteroparasitas patogênicos ao homem como Ascaris sp, Giardia sp, Strongyloides sp e Hymenolepis nana.

Duas hortas foram flagradas utilizando água de córregos na irrigação das verduras. A análise de uma delas (horta $n$ - 13) revelou elevada concentração de coliformes fecais na água mas não foi possível a coleta de verduras pela inexistência de seu cultivo, restrito a produtos rasteiros (beringela, tomate e pepino). Em duas visitas posteriores à mesma horta, a análise da água, assim como de verduras, evidenciou boas condições de higiene. A segunda horta (horta $\mathrm{n}^{\circ}$ 23), evidenciou contaminação de verduras mas não da água de irrigação.

A reavaliação das hortas apresentando irregularidades revelou persistência de contaminação em 3 análises sucessivas em apenas uma delas (horta $n^{\circ}$ 12), o que determinou sua interdição. Todas as demais obtiveram aprovação nos exames laboratoriais. 


\section{DISCUSSÃO}

As doenças transmitidas por alimentos são resultantes predominantemente do ciclo de contaminação fecal/oral e seu controle tem recebido atenção cada vez maior em todo o mundo 348121417 . No Brasil, não obstante a relevância e atualidade do problema, são poucos os trabalhos avaliando a qualidade das hortaliças consumidas pela população.

Gelli et $a{ }^{10}$ encontraram ancilostomídeos em $59,3 \%$ e Strongyloides spem 5,3\% de 113 amostras de verduras comercializadas no município de São Paulo. Em Ribeirão Preto, Marzochi ${ }^{16}$ detectou elevados níveis de enteroparasitas em hortaliças. Estes dados justificam a elevada freqüência de enteroparasitoses ${ }^{25}$ e da cisticercose ${ }^{23}$ no nosso meio.

A escolha da alface, entre outras hortaliças, foi motivada pela grande difusão de seu consumo sob a forma crua, pela facilidade de produção e possibilidade de contaminação por água de irrigação inadequada ${ }^{16}$.

Nosso estudo evidenciou que $20,1 \%$ das hortas apresentavam irregularidades, sendo a mais freqüente a contaminação por coliformes fecais de verduras (17\%). O exame microbiológico detectou também diferentes tipos de Salmonella em 3,1\% das verduras: $S$. Abaetetuba, $S$. Enteriditis, $S$. Schwarzengrunde a subespécie $S$. hountenae, considerados patogênicos ao homem ${ }^{11}{ }^{24}$. O exame parasitológico evidenciou a presença de enteroparasitas em 13,1\%: ancilostomídeos em 8,5\%, Entamoeba sp em 7,7\%, Hymenolepis nana em $1,5 \%$, Giardia sp em $0,7 \%$, Strongyloides $s p$ em $0,7 \%$ e Ascaris sp em $0,7 \%$. A detecção de Entamoeba sp e de ancilostomídeos, nem sempre patogênicos ao homem, foi valorizada somente em concomitância a uma elevada concentração de coliformes fecais, indicando a ocorrência de contaminação fecal. Estes resultados foram inferiores aos obtidos por Silva et $\mathrm{al}^{22}$ que, analisando hortaliças comercializadas em supermercados do Rio de Janeiro, detectaram helmintos em $21,4 \%$ das amostras. Oliveira \& Germano ${ }^{18}$, por sua vez, constataram, em São Paulo, enteroparasitas em $32 \%$ na alface lisa e em $34 \%$ na crespa, chegando a $66 \%$ no agrião. Silva et $\mathrm{a}^{22}$ e Oliveira \& Germano ${ }^{18}$ detectaram, ainda, ovos de Taenia sp, numa freqüência de $0,5 \%$ e $2,5 \%$, respectivamente. O achado de ovos de Taenia sp na alface foi também confirmado por Marzochi ${ }^{16}$ em Ribeirão Preto, embora sem o relato da freqüência. No presente estudo, apesar da não constatação especificamente de ovos de Taenia $s p$, a elevada freqüência de contaminação fecal permite supor que o consumo de verduras cruas possa justificar a elevada prevalência da cisticercose no município ${ }^{23}$.

O lançamento de esgoto doméstico sem tratamento prévio nos rios e córregos é prática usual e a utilização desta água na irrigação de hortas possibilita a contaminação fecal de verduras $^{21}$. Em Ribeirão Preto, esta irregularidade foi constatada em 1974 em hortas localizadas na região sudoeste do município ${ }^{16}$. O presente estudo demonstra que, a despeito da proibição legal, esta prática ainda persiste, duas décadas após, embora em escala menor.

A repetição dos exames das hortas reprovadas determinou a interdição de uma delas pela persistência de irregularidades. Todas as demais apresentaram boas condições higiênicosanitárias, comprovando a eficácia do sistema de fiscalização.

Deve-se no entanto ressalvar que este estudo não permite assegurar a qualidade da verdura consumida pela população pois o transporte e a manipulação nos pontos de venda podem acarretar a contaminação por microorganismos. Adicionalmente, embora a maior parte das verduras consumidas pela população do município seja proveniente das hortas avaliadas, alguns estabelecimentos adquirem produtos oriundos de outras localidades. Por conseguinte, a fiscalização deve ser expandida, abrangendo também os pontos de venda final ao consumidor.

A fiscalização de hortas, consubstanciada em análises laboratoriais sistematizadas e periódicas, assume papel fundamental no controle de qualidade das verduras com aplicação de penalidades rigorosas aos infratores, incluindo interdição dos reincidentes. Em contrapartida, as hortas apresentando boas condições higiênico-sanitárias devem ser oficialmente galardoadas e, para isto, o certificado de vistoria sanitária, emitido pela Secretaria Municipal da Saúde, pode constituirse numa possível solução. Embora sem o caráter obrigatório como o da carne, este certificado representa um estímulo ao produtor no aprimoramento da qualidade da hortaliça. Além da aprovação nos exames laboratoriais, sua 
concessão foi condicionada à apresentação da carteira de saúde dos manipuladores de verduras, com negatividade do exame coproparasitológico e atualização da carteira de vacinação. Esta iniciativa, pioneira no Brasil, demonstrou ser um instrumento valioso para melhor aceitação da fiscalização por parte dos produtores que exibem, até com orgulho, este documento nas feiras-livres onde muitos deles comercializam seu produto. Paralelamente, a divulgação do sistema de fiscalização nos meios de comunicação permitiu a consolidação desta iniciativa.

Sugerimos que este tipo de investigação e de fiscalização seja implantado em outras localidades, particularmente com a criação do certificado de vistoria sanitária, assegurando melhor qualidade dos alimentos oferecidos à população e contribuindo, decisivamente, para o controle das graves moléstias por eles transmitidas.

\section{AGRADECIMENTOS}

Aos Srs. Luiz Antonio Mafud, Antonio José Beordo e Vanderlei Greggi, fiscais sanitários da Divisão de Vigilância Sanitária da Secretaria da Saúde de Ribeirão Preto, pelo incansável trabalho em campo; às Sras. Maria José C.B. Bettini, Solange A.V. Oliveira, Maria Clarice
Errera e Dra. Ana Célia Mangini, do Instituto Adolfo Lutz, pelo apoio na análise laboratorial, e ao Prof. Dr. Gutemberg M. Rocha, da Faculdade de Medicina de Ribeirão Preto/USP, pela análise crítica do manuscrito.

\section{REFERÊNCIAS BIBLIOGRÁFICAS}

1. American Public Health Association. Technical Commitee on Microbiological Methods for Foods. In: Vanderzant C, Splittstoesser DF (eds) Compendium of methods for the microbiological examination of foods. $3^{\text {rd }}$ edition, American Public Health Association, Washington, p. 336-383, 1992.

2. American Public Health Association. Standard methods for the examination of water and wastewater. $18^{\text {th }}$ edition, American Public Health Association, Washington, p. 445, 1992.

3. Blaser MJ. How safe is our food? New England Journal of Medicine 334:1325-1326, 1996.

4. Borgdorff MW, Motarjemi Y. Surveillance of foodborne diseases: what are the options? World Health Statistics Quarterly 50:12-23, 1997.

5. Centers for Disease Control and Prevention. Incidence of foodborne illnesses. Morbidity and Mortality Weekly Report 47:782-786, 1998.

6. Centro de Vigilância Sanitária. Portaria no 21 de 19 de Dezembro de 1991. Diário Oficial do Estado, São Paulo, 24 de Dezembro de 1991.

7. Christovão DA. Condições sanitárias das águas de irrigação de hortas do município de São Paulo. IDeterminação da intensidade de poluição fecal através NMP de coliformes e de E. coli. Revista de Saúde Pública 1:3-11, 1967

8. D'Aoust JY. Salmonella and the international food trade. International Journal of Food Microbiology 24(1-2):11-31, 1994.

9. Divisão Nacional de Vigilância Sanitária de Alimentos. Secretaria Nacional de Vigilância Sanitária. Diário Oficial da União, Portaria no 451, de 19 de Setembro de 1997, Brasília, Seção I, p. 4, 1998.
10. Gelli DS, Tachibana T, Oliveira IR, Zamboni CQ, Pacheco JA, Spiteri N. Condições higiênico-sanitárias de hortaliças comercializadas na cidade de São Paulo, SP, Brasil. Revista do Instituto Adolfo Lutz 39:37-43, 1979.

11. Gomez TM, Motarjemi Y, Miyagawa S, Käferstein FK, Stöhr K. Foodborne salmonellosis. World Health Statistics Quarterly 50:81-89, 1997.

12. Guthmann JP. Epidemic cholera in Latin America: spread and routes of transmission. Journal of Tropical Medicine Hygiene 98:419-427, 1995.

13. International Commission on Microbiological Specifications for Foods. Microorganisms in foods: their significance and methods of enumeration. University of Toronto, Toronto, 1978.

14. Käferstein FK. Food safety: a commonly underestimated public health issue. World Health Statistics Quarterly 50:3-4, 1997.

15. Lennette EH, Balows A, Hausler WJ, Truant JP. Manual of clinical microbiology. $4^{\text {th }}$ edition, American Society for Microbiology, Washington, 1985.

16. Marzochi MCA. Estudo epidemiológico da poluição por enteroparasitas em áreas de horticultura da cidade de Ribeirão Preto, SP, Brasil. Tese de Doutorado, Universidade Estadual de Londrina, Londrina, PR, 1974.

17. Motarjemi Y, Käferstein FK. Global estimation of foodborne diseases. World Health Statistics Quarterly 50:5-11, 1997.

18. Oliveira CAF, Germano PML. Estudo da ocorrência de enteroparasitas em hortaliças comercializadas na região metropolitana de São Paulo, SP, Brasil. I- Pesquisa de helmintos. Revista de Saúde Pública 26:283-289, 1992. 
19. Oliveira CAF, Germano PML. Estudo da ocorrência de enteroparasitas em hortaliças comercializadas na região metropolitana de São Paulo, SP, Brasil. II- Pesquisa de protozoários intestinais. Revista de Saúde Pública 26:332-335, 1992.

20. Pattoli D, Paim GV. Enteroparasitas de águas de irrigação de hortas que abastecem o município de São Paulo. Revista Paulista de Medicina 68:241, 1966.

21. Rosas I, Báez A, Coutiño M. Bacteriological quality of crops irrigated with wastewater in the Xochimilco plots, Mexico city, Mexico. Applied and Environmental Microbiology 47:1074-1079, 1984.

22. Silva JP, Marzochi MCA, Camillo-Coura L, Messias AA, Marques S. Estudo da contaminação por enteroparasitas em hortaliças comercializadas nos supermercados da cidade do Rio de Janeiro. Revista da Sociedade Brasileira de Medicina Tropical 28:237-241, 1995.

23. Takayanagui OM, Castro e Silva AAC, Santiago RC, Odashima NS, Terra VC, Takayanagui AM. Notificação compulsória da cisticercose em Ribeirão Preto-SP. Arquivos de Neuropsiquiatria 54:557-564, 1996.

24. Taunay AE, Fernandes SA, Tavechio AT, Neves BC, Dias $\mathrm{AM}$, Irino $\mathrm{K}$. The role of public health laboratory in the problem of salmonellosis in São Paulo, Brazil. Revista do Instituto de Medicina Tropical de São Paulo 38:119127, 1996.

25. Waldman EA, Chieffi PP. Enteroparasitoses no Estado de São Paulo: questão de saúde pública. Revista do Instituto Adolfo Lutz 49:93-99, 1989. 